\title{
LIST OF BRITISH REPRESENTATIVES IN KASHGAR
}

1891

February 1904

September 1908

August 1918

May 1922

July 1922

September 1924

July 1925

October 1927

October 1930

September 1931

November 1933

October 1936

October 1938

November 1940

October 1942

March 1925

January 1946-8
G. Macartney (Assistant for Chinese Affairs to the Resident in Kashmir)

G. Macartney (consul - as recognised by Britain only)

G. Macartney (consul; consul-general from 1910)

P. Etherton

N. Fitzmaurice

C. P. Skrine

R. A. Lyall

G. V. B. Gillan

F. Williamson

G. Sherriff

N. Fitzmaurice

J. W. Thomson-Glover

K. C. Packman

H. H. Johnson

E. Shipton

M. C. Gillett

R. G. Etherington Smith

E. Shipton 